\title{
USER-DEFINED CLASSIFICATION ON THE ONLINE PHOTO SHARING SITE FLICKR...OR, HOW I LEARNED TO STOP WORRYING AND LOVE THE MILLION TYPING MONKEYS
}

\author{
Megan Winget <megan@ischool.utexas.edu> \\ School of Information \\ University of Texas at Austin \\ Sanchez Building, $562 \mathrm{~L}$ \\ 1 University Station, D7000 \\ Austin, TX 78712-0390, USA
}

\section{Introduction}

As evidenced by the growing popularity of sites which provide tagging and annotation functionality, like del.icio.us (http://del.icio.us), Flickr (http://www.flickr.com/), technorati (http://www.technorati.com/), and CiteULike (http://www.citeulike.org/), which already have combined user bases in the several millions, collaborative cataloging, or tagging, provides a workable solution for content organization, use, and exploration for many Internet users. This explosion in user-defined metadata has the potential to improve the way information is organized, navigated, and experienced on the web, and offers the Library and Information Science community the opportunity to augment and refine our existing classification methods and schemes to be more user-friendly, to allow for higher levels of precision and recall, and to enhance the human information interaction experience.

The collaborative cataloging movement is not without its critics. One of the more common concerns is related to control: namely, that there doesn't seem to be any. Critics contend that because these tagging systems are user-defined and operated, they have no vocabulary or authority control; no mechanism for hierarchically structuring vocabularies, and no policies for recording appropriate or useful metadata for a given piece of content. While these criticisms might have been valid in the early days of folksonomies and tagging (these many thirteen months ago), they are becoming less and less compelling with each passing day. This paper will address the concerns related to authority and control through focused exploration and description of one of the more popular social tagging sites, Flickr (http://www.flickr.com). After providing a brief background and introduction to Flickr's social and practical functionalities, this paper will focus on describing the site's various tagging utilities and related exploration tools, addressing the tripartite concerns regarding the lack of vocabulary control, hierarchical organization, and the policies and procedures that allow for successful classification. 
Winget, M. (2006). User-defined classification on the online photo sharing site Flickr...or, how I learned to stop worrying and love the million typing monkeys. 17th Annual ASIS\&T SIG/CR Classification Research Workshop, 1-16. doi: 10.7152/acro.v17i1.12496

17th SIG/CR Classification Research Workshop, November 4, 2006

\section{Flickr}

Flickr is defined as an "online image sharing community" and was originally created by Stewart Butterfield as a support tool for a web-based massively multiplayer online game, called Game Neverending. Because of its history in gaming and social networking, Flickr has, and always has had, a number of functionalities that are not typically associated with traditional online photo sharing sites such as iFoto and snapfish. For example, early incarnations of Flickr included "FlickrLive," which allowed for real-time photo exchange within a multi-user chat room. Currently, Flickr users can: organize, batch upload, edit, and define access and rights to their images within the application. Flickr's tagging utility, for which the company has understandably become somewhat famous, has been available from the earliest stages of development.

\subsection{Tags}

Tagging and annotation are powerful tools, giving users unprecedented power to mold and influence the way they experience the information with which they interact. Flickr allows users to define and assign multiple one-word tags to their own and others' images. These tags allow for ease of organization, retrieval and exploration, and users seemingly appreciate the opportunity to use and create them. For example, in February 2005, 62\% of the images stored on Flickr, 2.74 million images, had at least one tag (Butterfield, 2005). And over the last year, Flickr users have added, on average, over one million tags per week to the dataset (Dubinko, 2006). In addition to assisting in organization and indexing, Flickr's tagging tool allows users to build communities and unique narrative experiences around their images, define their own individual organizational structure on top of the standard base content, and to explore personal image clusters which are query defined and highly malleable.

In addition to allowing users to title and explain their images in narrative form, Flickr provides five different descriptive features, illustrated in figure 1: Tags, which are user-defined keywords that describe the context and/or content of an image or group of images; Notes, a Flash-based application that allows image creators and registered users to select a portion of an image to "annotate" in whatever way they find appropriate; Comments, where visitors can make editorial, conversational or aesthetic comments on an individual image; "Favorites," where a user will mark an image as one of their "favorites" for collection and subsequent perusal; and Contacts, defining a specific creator as a person worth watching. Additionally, users can create 'sets' of their own images with similar characteristics, and define their images as belonging to a 'pool,' which includes images from different users that have common 
characteristics. This paper will focus on tags, the user-defined keywords that describe an image's context or content.

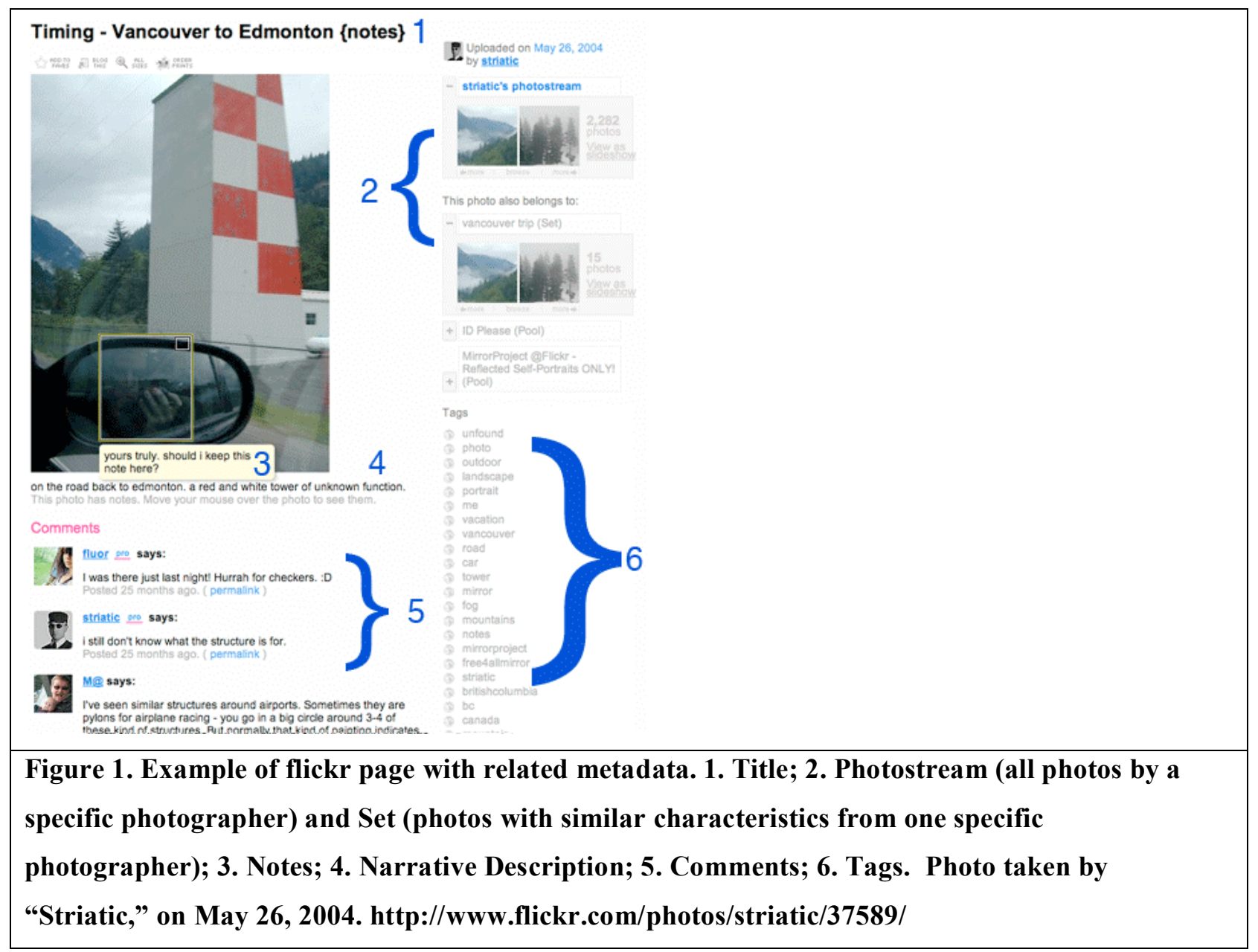

Although user-defined and freeform, flickr tags tend to naturally fall into five categories:

- Date and time (for example: june11,06111999, 0611, samsbirthday),

- Geographical (for example: rome, trevifountain, geo:lat=41.900920, geo:lon=12.483301 [=trevi fountain in rome]),

- Narrative (what would traditionally be called subject or keyword cataloging, for example: buildings, urban, city, newyorkcity, architecture, sunset),

- Characterizations, either of people or of situations (for example: me, mygirlfriend, susan, beautiful, happy);

- Individually defined tags which are related to games, social groups, narratives, or projects unique 
to Flickr (for example: mynecktie, pickleproject, 1000somethings, haiku, squaredcircle, happybirthday).

Tags can be any part of speech:

- Nouns (volcano, bear, bears, polarbears),

- Adjectives (yummy, beautiful, boring),

- Verbs (sit, run, jump),

- Adverbs (sweetly, swiftly), and even

- Prepositions (with, out, into).

One limitation of the Flickr system is that all tags must be one word. The examples above illustrate the type of concatenation that results. "New York City" becomes newyorkcity, or NYC, or newyork. Flickr users sometimes also use punctuation marks: "Mount Saint Helens" might become mountsainthelens, MountSaintHelens (with capitalization), Mt.St.Helens, or any combination of abbreviations thereof.

\section{Project Description}

For this project three noun-tags (volcano, polarbears, monterey) were chosen. For each tag four pieces of specific information was recorded: 1) the number of images returned in the tag-set; 2) the number of relevant returns (i.e., an image tagged "volcano" contains an object that could be a volcano); and, for the first one-hundred "interesting" returned images of each tag, 3) the related words in the tag set (for example: volcano, spew, lava, molten, smelly, augustine, eruption, alaska...), and 4), and the average number of tags for each image. In the case of each of these tags, we also looked for a specific image: for the search term "volcano," we wanted to find Mount Merapi in Indonesia. For the term "polarbears," we wanted to find images of those polar bears in the Central Park Zoo. And for "Monterey," we were looking for a specific image that could only be taken in Monterey, California: the jellyfish exhibit at the Monterey Bay Aquarium. Each of these tags presented opportunities for further exploration, which will be discussed in the individual sections below.

A tag search in Flickr results in a return of matching images. These images can either be ordered by "most recent," meaning those images most recently deposited in the system will be at the top of the returns, or by "most interesting." The qualities of "interesting" images are defined by the Flickr system, and the algorithm for determining an image's "interestingness" is not publicly available. The first one hundred 
Winget, M. (2006). User-defined classification on the online photo sharing site Flickr...or, how I learned to stop worrying and love the million typing monkeys. 17th Annual ASIS\&T SIG/CR Classification Research Workshop, 1-16. doi: 10.7152/acro.v17i1.12496

17th SIG/CR Classification Research Workshop, November 4, 2006

"interesting" images were used as the result set in this research project because both the creators and the images in this group were more diverse than in the "most recent" set. This diversity illustrated more variation in both the tagging methods and the subject matter of the returned set.

\subsection{Flickr Tag: Monterey}

The city of Monterey is located in Monterey County, on the Monterey Peninsula, and, in fact, on Monterey Bay. In Central California, about one hour south of San Francisco, Monterey (in all its forms) has significant physical tourist attractions, including "Cannery Row," a Steinbeckian shrine; the famous golf course Pebble Beach, and "17 mile drive," a scenic highway that outlines the peninsula shoreline. A nearby city, Carmel-by-the-Sea, is the starting point of "Route 1," also known as the "Pacific Coast Highway," which extends from Carmel to San Luis Obispo. This is all to say that there are a myriad of photo opportunities on a trip to Monterey California.

With the numerous "Monterey" descriptors (The city, the county, the peninsula, and the bay), we were particularly interested in looking at the degree to which the Flickr system could disambiguate the different types of images. For example, a picture taken on the Monterey Peninsula, and hence reliably tagged "Monterey," could have actually been taken in the city of Carmel, or even on the Pacific Coast Highway.

The Flickr system returned 41,823 images for the term "Monterey." Of the first 100 returned "interesting" images, 89 were considered "relevant," having been taken in the city of Monterey (59\%), or on the Monterey Peninsula (41\%). Of the 11 images defined in this study as "not relevant" five were pictures of people taken in hotels, two were misspellings of Monterrey Mexico, and 3 were simply mis-tagged (Santa Cruz, San Simeon, and somewhere South along the Pacific Coast Highway). It could be argued that the images from hotels were probably taken in Monterey, but because they had no distinguishing characteristics specific to the tag, they were defined as not relevant. Additionally, those images that were obviously not taken in Monterey might very well have been taken on a "Monterey trip." San Simeon, for example is an easy drive from Monterey, and many day trips to San Simeon originate in Monterey.

There was an average of 11.68 descriptive tags per "Monterey" image, with five images having three tags or less, and five having between twenty and twenty-five tags.

We were looking for a specific type of image that could only be taken in the city of Monterey: a picture of the jellyfish exhibit at the Monterey Bay Aquarium. Because there is such an abundance of possible 
Winget, M. (2006). User-defined classification on the online photo sharing site Flickr...or, how I learned to stop worrying and love the million typing monkeys. 17th Annual ASIS\&T SIG/CR Classification Research Workshop, 1-16. doi: 10.7152/acro.v17i1.12496

17th SIG/CR Classification Research Workshop, November 4, 2006

images in this area, we thought that there might be a few taken in the Aquarium, and perhaps a couple of the jellyfish exhibit specifically. Surprisingly, only 44\% (40) of the images tagged with "Monterey" were scenic or landscape images, taken either on the 17-mile drive, the Pacific Coast Highway, or somewhere else on the Monterey peninsula. The majority of the images, $58 \%$, were taken in the aquarium: $37 \%$ (33) were of the jellyfish exhibit specifically, and $21 \%$ (19) were taken of other exhibits in the aquarium.

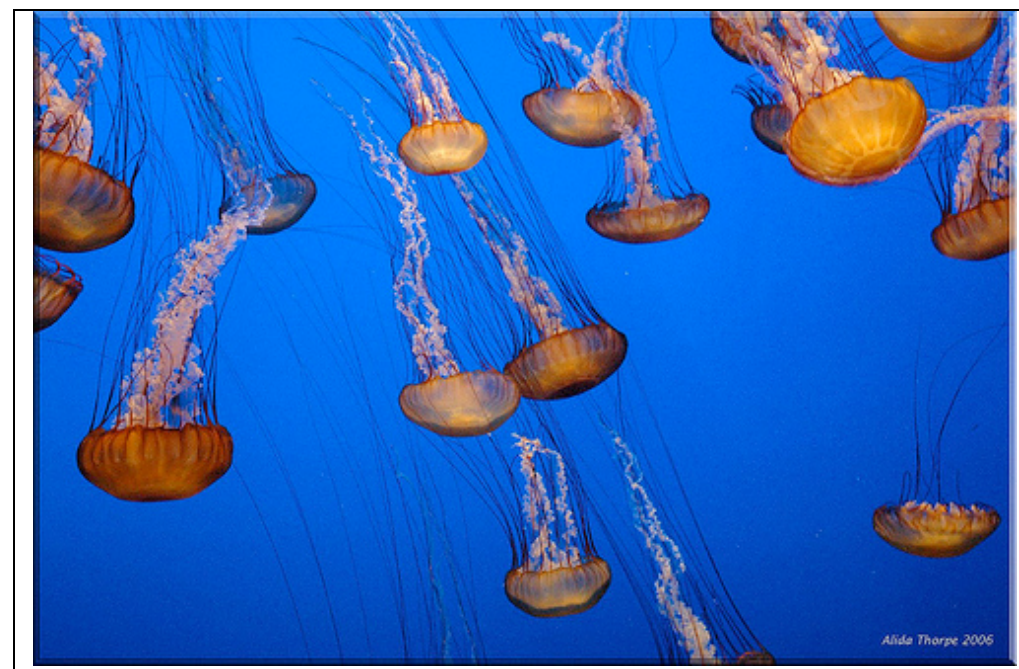

Figure 2. "I couldn't resist" taken by "alidasphotos."

http://www.flickr.com/photos/alidasphotos/100705693/ (titled: I couldn't resist)

There was only one cluster of images related to "Monterey," which had tags of California, aquarium, and jellyfish. The Flickr system was unable to differentiate between the different kinds of "Monterey" images; for example, there were no clusers of landscapes, seascapes, and highways - which would be expected given knowledge of the topography of the area. Related tags used by five or more images include: aquarium, bay, beach, BigSur, bird, blue, California, central coast, fish, flowers, highway1, jellies / jelly / jellyfish, marine, MontereyAquarium, MontereyBay, MontereyBayAquarium, nature, ocean, pacific / PacificOcean / PacificCoast / PacificCoastHighway, sea, SeaCreatures, SeaJellies, SeaLife, SeaLion, SeaNettle, SeaOtter, silhoutte, sunset, underwater, water.

\subsection{Flickr Tag: Polar Bears}

The Flickr system returned 1001 images tagged "polarbears." Of the 100 top "interesting" images, only three were not relevant, being pictures of: a flamingo, a white wedding cake, and a person looking at a polar bear (but no polar bears in the picture). Of the 97 remaining pictures, there were 84 images of animal-polar-bears, and 13 images of human-polar-bears, people that belong to the "polar bear club" who, 
on New Years Day, gather at Coney Island New York, to take a subzero dip in the Atlantic Ocean. In this case, Flickr's clustering algorithm was able to distinguish between humans and animals, in that there is a cluster of human polar bears, animal polar bears in the Central Park Zoo, and animal polar bears in all other zoos. (figure 3).

\section{Explore / Tags / polarbears / clusters}

Jump to: polarbear
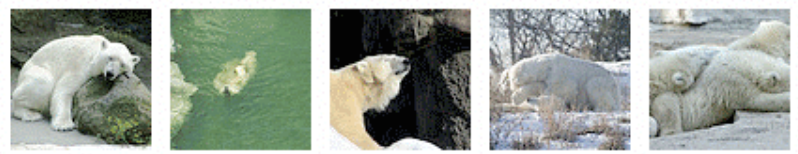

bears, zoo, animals, bear, animal, polarbear, sandiego, polar, zoos, seaworld

$\rightarrow$ See more in this cluster...
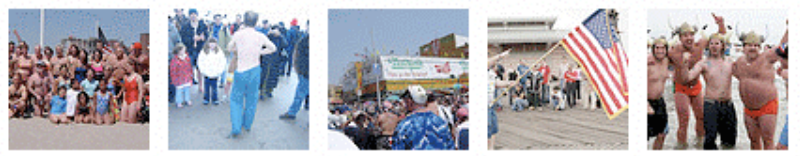

brooklyn, coneyisland, beach

$\rightarrow$ See more in this cluster...
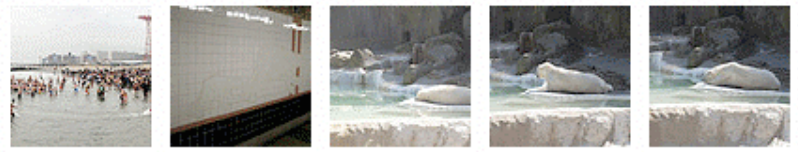

nyc, centralpark, newyork

$\rightarrow$ See more in this cluster...

Figure 3. "Polarbears" Clusters (captured 7/12/2006)

http://www.flickr.com/photos/tags/polarbears/clusters/

However, there is a clustering problem in that human polar bears show up in the NYC / Central Park Zoo cluster, the bottom group of images in figure 3. This particular problem did not exist for the term "polarbear," probably because the human-polar-bears were always referred to in the plural.

There were an average of 11.79 tags per "polarbears" image. Those related words that were used to describe five or more images include: dates [date of the zoo visit], animal / animals, bear / bears, blue, DetroitZoo, EdinburghZoo, fjord, glacier, Greenland, huskies, mammal/s, Michigan, nature, NCzoo, play/ful/ing, SanDiegoZoo, swimming, underwater, water, wildlife.

It was very easy to find pictures of the polar bears in Central Park Zoo. In fact, we hoped to find a very specific image of one of the Central Park Zoo polar bears leaning against the glass divider in a specific way. It turns out that this image was in the top ten "interesting" images for the cluster of "polar bears" and "Central Park Zoo," and is illustrated in figure 4. 


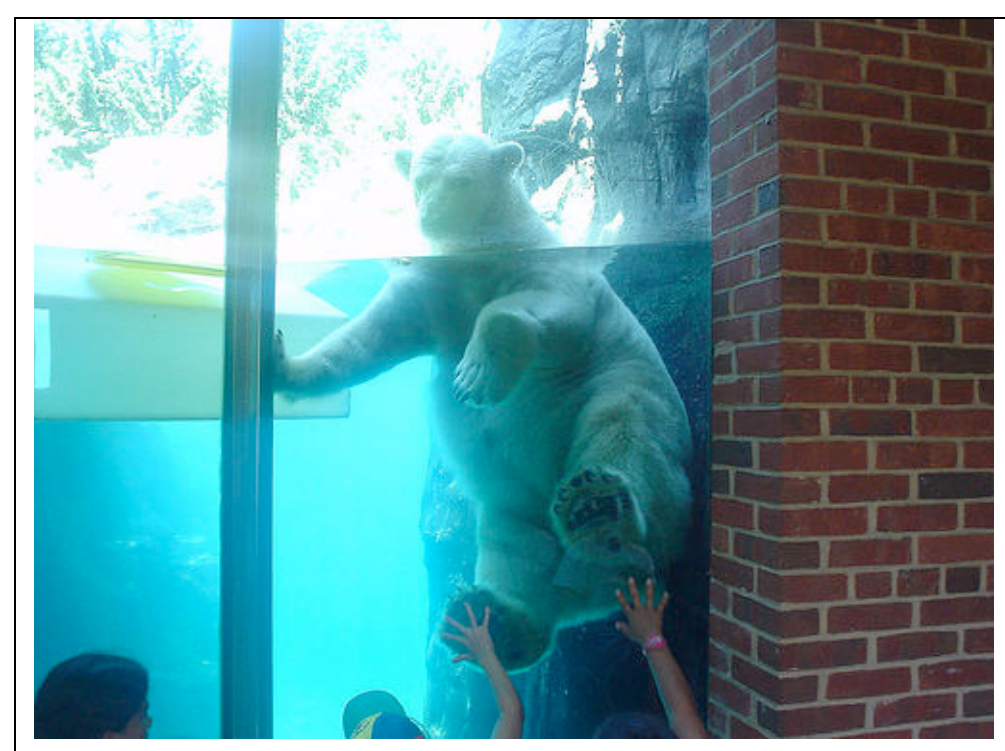

Figure 4. "Polar Bear" taken by "markhurst." http://www.flickr.com/photos/markhurst/25089008/

\subsection{Flickr Tag: Volcano}

The Flickr system returned 24,623 images with the tag "volcano." There were four clusters: Hawaii (Volcano National Park), Washington State (Mt. Saint Helens), Italy (Vesuvius), and Costa Rica (Arenal Volcano). Eighty of the one hundred most interesting images were obviously images of volcanoes, either depicting eruptions or characteristic conical mountains. Of the remaining twenty images, eighteen were landscape images of mountainous areas, which could have been taken in a park surrounding a volcano, or on the slopes of a volcano, but were not obviously images of volcanos. Two were images of people, probably on a "volcano vacation," as evidenced by hiking gear and camping equipment.

There were an average of 20.89 tags per "volcano" image, with three images having less than six tags and seven images having between thirty-five and forty-two tags. Eighty-one of the hundred "most interesting" images were specifically named volcanoes, which allowed for reliability checks of user tagging against a known source, the Thesaurus of Geographic Names (TGN). Two aspects of users' tagging behaviors were compared against the TGN: 1) the degree to which the Flickr users chose "preferred" names over variants. Whether, for example, users tagged their images with the preferred name, Vesuvio, or one of the variants (Vesuvius, Mount Vesuvius, Le Vésuve, Vesubio, Vesuv). 2) We also looked at the degree to which Flickr users represented the hierarchical structure of place-name description. TGN's hierarchical description of Vesuvius, for example, is: World (facet) : Europe (Continent) : Italy (nation) : Campania 
Winget, M. (2006). User-defined classification on the online photo sharing site Flickr...or, how I learned to stop worrying and love the million typing monkeys. 17th Annual ASIS\&T SIG/CR Classification Research Workshop, 1-16. doi: 10.7152/acro.v17i1.12496

17th SIG/CR Classification Research Workshop, November 4, 2006

(region) : Napoli (province) : Vesuvius (volcano). We were interested in looking at how many of those terms Flickr users chose to include in their tagging schema.

When looking at the degree to which Flickr users chose the "preferred name" for their volcanoes, we found that 14 of those named volcanoes are not in the TGN, although the names are correct (as determined by web search). In 6 cases, the closest city, probably named after the volcano, was in the TGN, but not the volcano itself. Those places are listed in table 1. "Not in TGN" means that there is no listing of this volcano anywhere in the TGN, either by the listed name or any variants that could be found.

Table 1. Named Places not in TGN

\begin{tabular}{|l|l|l|}
\hline Volcano Name & Country & Closest TGN entry \\
\hline Grimsnes Volcano & Iceland & Not in TGN \\
\hline Rangitoto Island - Volcano & Auckland, NZ & Not in TGN \\
\hline Waitopo & Auckland, NZ & Not in TGN \\
\hline Mount Pacaya & Guatemala & Not in TGN \\
\hline Rabaul Volcano & Papua New Guinea & Rabaul (Inhabited Place) \\
\hline Roche Tuiliere & France & La Tuiliere (Inhabited Place) \\
\hline Laguna Colorada & Bolivia & Not in TGN \\
\hline Tangkuban Perahu & Indonesia & Not in TGN \\
\hline Lago Caburga & Chile & Not in TGN \\
\hline Parinacota & Bolivia & Not in TGN \\
\hline Ranu Raraku & Easter Island & Not in TGN \\
\hline Stromboli Volcano & Italy & Stromboli Isola (Island) \\
\hline Calbuco Volcano & Chile & Calbuco (Inhabited Place) \\
\hline Osorno Volcano & Chile & Osorno (Inhabited Place) \\
\hline Llanquihue Lake & Chile & Llanquihue (Inhabited Place) \\
\hline
\end{tabular}

Table 2 shows all of the "preferred" and alternate names for the volcanoes specifically named in the Flickr set, which had more than one designation in the TGN. In four of the five cases (Vesuvio, Fujisan, Bromo Gundung, Mount Rainier), Flickr users tagged the image with the preferred name of the volcano. In three of the same cases, users also provided at least one alternate name. Only Kilauea and Mount Rainier were not tagged with alternate names, and only the image of Kilauea was not tagged with the preferred name. 
Table 2. Preferred and Alternate Volcano Names Compared to Flickr's Users' Tags.

\begin{tabular}{|c|c|c|}
\hline Volcano & TGN Designations & Flickr Names \\
\hline Mount Vesuvius & $\begin{array}{l}\text { Vesuvio (preferred,C,V,N) } \\
\text { Vesuvius }(\mathrm{C}, \mathrm{O}, \mathrm{N}, \text { English-P) } \\
\text { Mount Vesuvius (display,C,O,N,English) } \\
\text { Vesuvius, Mount (C,O,N,English) } \\
\text { Le Vésuve }(\mathrm{C}, \mathrm{O}, \mathrm{N}) \\
\text { Vesubio }(\mathrm{C}, \mathrm{O}, \mathrm{N}) \\
\text { Vesuv }(\mathrm{C}, \mathrm{O}, \mathrm{N})\end{array}$ & $\begin{array}{l}\text { Vesuvio } \\
\text { Vesuvius }\end{array}$ \\
\hline Mount Kilauea & $\begin{array}{l}\text { Kilauea Crater (preferred,C,V,N) } \\
\text { Kilauea }(\mathrm{C}, \mathrm{V}, \mathrm{N}) \\
\text { Kilauea Caldera }(\mathrm{C}, \mathrm{V}, \mathrm{N}) \\
\text { Kirauea }(\mathrm{C}, \mathrm{V}, \mathrm{N}) \\
\text { Lahainaluna }(\mathrm{C}, \mathrm{V}, \mathrm{N}) \\
\text { Lua Peleo Kilauea }(\mathrm{C}, \mathrm{V}, \mathrm{N})\end{array}$ & Kilauea \\
\hline Mount Fuji & $\begin{array}{l}\text { Fuji-san (preferred,C,V,N) } \\
\text { Fujiyama }(\mathrm{C}, \mathrm{V}, \mathrm{N}) \\
\text { Fuji-no-Yama }(\mathrm{C}, \mathrm{V}, \mathrm{N}) \\
\text { Fuji San }(\mathrm{C}, \mathrm{V}, \mathrm{N}) \\
\text { Fuji, Mount }(\mathrm{C}, \mathrm{O}, \mathrm{N})\end{array}$ & $\begin{array}{l}\text { Fuji } \\
\text { Fujisan } \\
\text { Fujiyama } \\
\text { MountFuji } \\
\text { Mt.Fuji }\end{array}$ \\
\hline Mount Bromo & $\begin{array}{l}\text { Bromo, Gunung (preferred,C,V,N) } \\
\text { Bromo }(\mathrm{C}, \mathrm{V}, \mathrm{N})\end{array}$ & $\begin{array}{l}\text { Bromo } \\
\text { GunungBromo } \\
\text { BromoGunung } \\
\text { MountBromo }\end{array}$ \\
\hline Mount Rainier & $\begin{array}{l}\text { Rainier, Mount (preferred,C,V,N) } \\
\text { Mount Tacoma }(\mathrm{C}, \mathrm{V}, \mathrm{N})\end{array}$ & $\begin{array}{l}\text { Mt.Ranier } \\
\text { MountRainier } \\
\text { Rainier }\end{array}$ \\
\hline
\end{tabular}

Table 3 illustrates the degree to which Flickr users tagged their images using hierarchical terms as determined by the TGN. This table shows the preferred volcano name, the number of images of that volcano in the Flickr set, the TGN hierarchy, and the geographic terms chosen by Flickr users. The table shows that Flickr users almost always included all the terms in the TGN hierarchy, except for the "world" facet designation, and in many cases include extra information not included in the TGN. For example, 
Mount Augustine, an active volcano on the Kenai Peninsula, was described using all of the terms defined by the TGN, like "America, Alaska, Kenai Peninsula, and Augustine Volcano," but Flickr users also included additional terms, like "HomerAlaska," the nearest town, and "CookInlet" the closest inlet to the volcano. Flickr users describe Mount Taranaki, in New Zealand, using both its aboriginal and anglicized names: Mount Taranaki and Egmont; and the person who tagged the images of Mount Vesuvius gave both Italian and English versions of all the major geographical descriptors (Italy / Italia, Vesuvio / Vesuvius, and Naples / Napoli - the province).

Table 3. Comparison of TGN and Flickr User-Defined Geographic Tags

\begin{tabular}{|c|c|c|c|}
\hline Volcano Name & \# Images & TGN Hierarchy & Flickr Geographic Terms \\
\hline \multirow[t]{9}{*}{ Mount Augustine } & \multirow[t]{9}{*}{13} & World (facet) & Alaska / AK \\
\hline & & $\begin{array}{l}\text { North and Central } \\
\text { America (continent) }\end{array}$ & Alaskamountain / s \\
\hline & & United States (nation) & AK / alaskapeninsula \\
\hline & & Alaska (state) & America \\
\hline & & $\begin{array}{l}\text { Kenai Peninsula } \\
\text { (national division) }\end{array}$ & Cookinlet / AK \\
\hline & & $\begin{array}{l}\text { Augustine Volcano } \\
\text { (peak) }\end{array}$ & Homer / AK / Alaska \\
\hline & & & Kenaipeninsula / AK / Alaska \\
\hline & & & MountAugustine / volcano \\
\hline & & & MtAugustine / volcano \\
\hline \multirow[t]{5}{*}{ Volcán Atitlán } & \multirow[t]{5}{*}{2} & World (facet) & America \\
\hline & & $\begin{array}{l}\text { North and Central } \\
\text { America (continent) }\end{array}$ & Atitlan \\
\hline & & Guatemala (nation) & CentralAmerica \\
\hline & & Sololá (department) & Central \\
\hline & & $\begin{array}{l}\text { Atitlán, Volcán } \\
\text { (volcano) }\end{array}$ & Guatemala \\
\hline \multirow[t]{2}{*}{ Volcán Arenál } & \multirow[t]{2}{*}{4} & World (facet) & Arenal \\
\hline & & & ArenalVolcon \\
\hline
\end{tabular}

North and Central 


\begin{tabular}{|c|c|c|c|}
\hline & & America (continent) & \\
\hline & & Costa Rica (nation) & CostaRica \\
\hline & & Alajuela (province) & FortunaArea \\
\hline & & $\begin{array}{l}\text { Arenal, Volcán } \\
\text { (volcano) }\end{array}$ & \\
\hline Mount Taranaki & 2 & World (facet) & NewZealand \\
\hline [Egmont] & & Oceania (continent) & Egmont \\
\hline & & New Zealand (nation) & MountTaranaki \\
\hline & & $\begin{array}{l}\text { North Island } \\
\text { (nationaldivision) }\end{array}$ & NorthIsland \\
\hline & & Taranaki (region) & Taranaki(Mt.Egmont) \\
\hline & & $\begin{array}{l}\text { Taranaki, Mount } \\
\text { (mountain) }\end{array}$ & \\
\hline Vesuvio & 2 & World (facet) & Italia / Italy \\
\hline & & Europe (continent) & Golfo / gulf \\
\hline & & Italy (nation) & Naples / Napoli \\
\hline & & Campania (region) & Vesuvius / Vesuvio \\
\hline & & Napoli (province) & Campania \\
\hline & & Vesuvius (volcano) & \\
\hline Mount Rainier & 3 & World (facet) & Washington \\
\hline & & $\begin{array}{l}\text { North and Central } \\
\text { America (continent) }\end{array}$ & $\begin{array}{l}\text { Mt.Rainier / MtRainier / } \\
\text { MountRainier }\end{array}$ \\
\hline & & United States (nation) & Ranier \\
\hline & & Washington (state) & MountRainierNationalPark \\
\hline & & Pierce (county) & \\
\hline & & $\begin{array}{l}\text { Rainier, Mount } \\
\text { (mountain) }\end{array}$ & \\
\hline
\end{tabular}

\section{Conclusions}

One of the principal fears engendered by the collaborative cataloging phenomenon stems from fear of the uncontrollable. Within this movement there is no gate keeping utility, and users have much more control over the mechanisms of description and interaction than they do in the traditional models of collection 
Winget, M. (2006). User-defined classification on the online photo sharing site Flickr...or, how I learned to stop worrying and love the million typing monkeys. 17th Annual ASIS\&T SIG/CR Classification Research Workshop, 1-16. doi: 10.7152/acro.v17i1.12496

17th SIG/CR Classification Research Workshop, November 4, 2006

development and description. Although users might have the best intentions, the traditional argument goes, is it really possible for people uneducated in the intricacies of representation and classification to reliably describe their materials for retrieval and access purposes?

While Flickr does not provide a strict means of vocabulary control, there are loose standards to which many users try to conform when tagging their images (c.f., the "Flickr Central Discussion" Striatic 2004a and 2004b). This research project further suggests that users, especially if they are invested in the "success" of their images within the given system, at the very least have the best intentions in terms of description. Not only do they give their images multiple tags (an average of 14.79 tags per image for the three groups), they also provide specific geographical terms when appropriate, as well as multiple spellings, abbreviations, and concatenations of those terms. The geographical names are hierarchically sound in that the users include all or almost all of the hierarchical terms suggested by the TGN, even if those terms are not common knowledge, like the province that includes Vesuvius, for example. In most cases Flickr users also use the preferred name to describe the content of their images, even if that name does not happen to be in the photographer's native language. In this study, only one volcano, Kilauea, was not tagged with its preferred name, while multiple images were tagged with the preferred name along with multiple alternative names.

As an aside, on August 28, 2006, Flickr introduced a "geotagging" functionality internal to the Flickr system. Geotagging is a mechanism by which users can define exact latitude and longitude of their images, allowing for tie-ins with mapping applications like GoogleMaps. By the next day, August 29, there were 1.6 million geotagged photos in the system (Butterfield, 2006). For whatever reason, users want to tag their digital content. They enjoy doing it, and for the most part, they do a thorough, relevant, reliable, and interesting job of it.

Flickr-developed tools, like "interestingness" and the newly introduced "clustering" algorithm provide a service very much like hierarchical structure, which helps to disambiguate different types of images. Although the clustering algorithm is not perfect: i.e., it was unable to make distinctions between human and animal polar bears, it will only improve given time.

The final point of contention, that there are no policies for recording appropriate or useful metadata for a given piece of content, actually addresses the fundamental strength of a system like Flickr. Although Flickr users are tagging in terms of their own needs and experience, they seem to be doing so in a way that is complimentary to the needs and experience of other users. Because Flickr is essentially an 
enhanced social networking site, where relationships are built and strengthened; tagging, in addition to serving traditional purposes related to organization, retrieval and access, also brings together communities of people with similar interests. One can "subscribe" to any tag, for example, and be notified whenever anyone adds an image with that tag to the system (Figure 5). It is also possible to build "tag slideshows" for any tag, on the fly, and define "pools" of images that all contain the same tag - and therefore build a community around that tag.

\begin{tabular}{|c|c|c|c|c|}
\hline & A-DAILY & & II b architechture & $44 \mapsto \Leftrightarrow$ \\
\hline 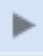 & Art & 1 & \multirow{2}{*}{ TOUR EIFFEL 2} & \multirow{2}{*}{$\star$ NEW $\odot$} \\
\hline$\triangleright$ & Cite-U-Like & 163 & & \\
\hline $\boldsymbol{\nabla}$ & \multicolumn{2}{|l|}{ Flickr Feeds } & \multirow{2}{*}{\multicolumn{2}{|c|}{$\begin{array}{l}\text { Published: Today, 1:28 PM } \\
\text { Author: nobody@flickr.com (6T) }\end{array}$}} \\
\hline \multicolumn{3}{|c|}{$\begin{array}{l}\text { A Retro Kid } \\
\text { No Items }\end{array}$} & & \\
\hline \multicolumn{3}{|c|}{ f $\begin{array}{l}\text { architechture } \\
\text { TOUR EIFFEL }\end{array}$} & $\underline{6 \mathrm{~T}}$ posted a photo: & \\
\hline \multicolumn{3}{|c|}{$\begin{array}{l}\text { f Catchy Colors } \\
\text { DSCN53202 }\end{array}$} & \multirow{5}{*}{ 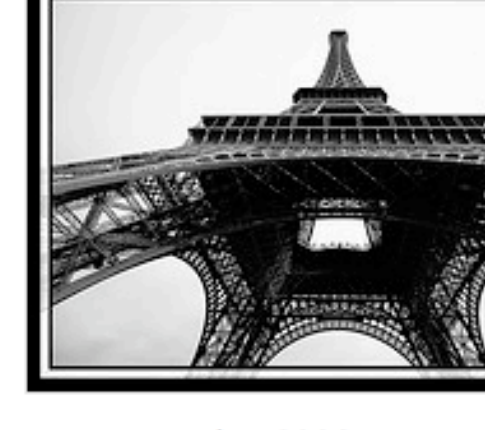 } & \\
\hline \multicolumn{3}{|c|}{$\begin{array}{l}\text { Creative Commons } \\
\text { Chicago Skyline - HDR }\end{array}$} & & \\
\hline \multicolumn{3}{|c|}{$f \begin{array}{l}\text { Eliacin } \\
\text { No Items }\end{array}$} & & \\
\hline \multicolumn{3}{|c|}{$\begin{array}{l}\text { Flickr Blog } \\
\text { Geotagging - one day later }\end{array}$} & & \\
\hline \multicolumn{3}{|c|}{$\begin{array}{l}\text { Stock Photos } \\
\text { This is why people appl... }\end{array}$} & & \\
\hline$\triangleright$ & News \& Politics & 87 & \multirow[t]{2}{*}{ Paris september 2006} & \\
\hline \multicolumn{3}{|c|}{$=\ldots$} & & \\
\hline & ure 5. Screensh & RSS & ggregator with Flickr Feed & cture" feed. \\
\hline
\end{tabular}

In Flickr, the tags support exploration, and make it possible for users to make new connections (both physical and intellectual), not predefined by the system itself. For example, if some person was taking a trip to Monterey California, and happened to view a slideshow of all the images tagged "Monterey" in the Flickr system, they would immediately get a sense of the "interesting" attractions in that area. Flickr would certainly not be the only source of information for a Monterey vacation, but these users would know that the Aquarium is an attraction worth thinking about, and the jellyfish exhibit is specifically interesting. This is not a "designated use" for the system, but the system architecture, which is fundamentally supported by the tagging mechanism, allows for new and innovative uses of the system with minimal overhead for Flickr programmers and staff. When one starts to consider that Flickr's use and functionality is only limited by the imagination of its users, it becomes clear that this is a pretty 
Winget, M. (2006). User-defined classification on the online photo sharing site Flickr...or, how I learned to stop worrying and love the million typing monkeys. 17th Annual ASIS\&T SIG/CR Classification Research Workshop, 1-16. doi: 10.7152/acro.v17i1.12496

17th SIG/CR Classification Research Workshop, November 4, 2006

powerful system. All it took, when everything is said and done, was trust in the users to describe their images reliably and authoritatively.

This paper was an attempt to begin a discussion about the way information is organized, navigated, and experienced on the web. Not only does user-defined metadata give the Library and Information Science community the opportunity to augment and refine our existing classification methods and schemes to be more user-friendly, this method of description might also allow for an enhanced the human information interaction experience. Findings from this study indicate that our traditional definitions of authority and our desire for control might need to evolve in this atmosphere of user-defined metadata and social networking focused on digital objects. Users have the best intentions, they tag their images extensively, and their terms are appropriate, thorough, and in many cases, authoritatively chosen. The Flickr staff seems to recognize the need for hierarchical structure, and is trying to provide that through their clustering tool, and other tools still under development. Finally, the strength of the social relationships of players within the system provides a mechanism for ambient and informal policies and procedures, which, although not official or strict, perform the function of enforcing appropriate tagging behavior. Finally, the spirit of trust and openness allows Flickr system developers to leverage users interests and work in powerful and innovative ways.

\section{References}

Butterfield, S. (2005). Founder and CEO, Ludicorp. San Francisco, California. Personal Correspondence. February 6, 2005.

Butterfield, S. (2006). Geotagging: One day later. Flickr Blog. Tuesday, August 29 [2006], 11:23 PM. Retrieved from http://feeds.feedburner.com/ r/Flickrblog/ 3/17553027/geotagging_one_.html.

Dubinko, M., Kumar, R., Magnani, J., Novak, J., Raghavan, P., and Tomkins, A. (2006). Visualizing tags over time. In Proceedings of the 15th International Conference on World Wide Web (Edinburgh, Scotland, May 23 - 26, 2006): 193-202. New York, NY: ACM Press. Retrieved from http://doi.acm.org/10.1145/1135777.1135810.

Striatic. (2004a). Tagging it up: Some suggestions for tagging your images. Groups. Flickr Central. Discussion Board. Retrieved from http://flickr.com/groups/central/discuss/2026/. 
Winget, M. (2006). User-defined classification on the online photo sharing site Flickr...or, how I learned to stop worrying and love the million typing monkeys. 17th Annual ASIS\&T SIG/CR Classification Research Workshop, 1-16. doi: 10.7152/acro.v17i1.12496

17th SIG/CR Classification Research Workshop, November 4, 2006

Striatic. (2004b). Tagography: Case studies. Groups. Flickr Central. Discussion Board. Retrieved from http://flickr.com/groups/central/discuss/2730/. 